\title{
Numerical Simulation of Scavenging Process of Large 2-Stroke Marine Diesel Engine
}

\author{
HE Faming ${ }^{1}$, Wei Jin ${ }^{2}$ \\ ${ }^{1 .}$ Qingdao Ocean Shipping Mariners college, Qingdao, 266071, China \\ 2. MAN Diesel \& Turbo Branch of MAN Diesel \& Turbo SE, Germany, Engineering and R\&D (DPAE) Niels Juels Vej 159900 \\ Frederikshavn, Denmark
}

\begin{abstract}
Computational Fluid Dynamics (CFD) is of great importance for R\&D of Large 2-Stroke Marine Diesel Engine. The CFD software ANSYS FLUENT was adopted to calculate the scavenging process of a large 2-stroke marine diesel engine MAN B\&W S60MC-C6 and the obtained pressure trace was compared with the shop test data. The swirl flow field was analyzed on the achieved satisfactory in-cylinder pressure agreement. This provides a good reference for the application of CFD to the optimization of large 2-stroke marine diesel engine scavenge process.
\end{abstract}

Keywords-CFD; large 2-stroke marine diesel engine; uni-flow scavenging; ANSYS FLUENT

\section{INTRODUCTION}

As the energy of mechanical equipment, internal combustion engine was first invented by the German inventor Otto in 1876. In 1892, another German inventor Diesel invented the marine diesel engine with diesel compression .Twenty years later, the first ship of the world propelled by diesel, Selandia achieved the maiden voyage in 1912 .Since then, as driving force machinery, and marine diesel engine has existed more than a century. In the middle 1950s, it greatly increased the efficiency of marine diesel engine and reduced transportation cost by the use of turbocharger and the lubricating oil. So far, the most efficient 2-stroke marine diesel engine thermal efficiency can reach about $55 \%{ }^{[1]}$.Although it is close to the limit of the fuel combustion efficiency, internal combustion engine companies still invested a lot of research and development team, in order to remain competitive in the market. At present, MAN Diesel \& Turbo of Denmark has close to $90 \%$ of the market share in 2 -stroke marine diesel engine; another $10 \%$ belongs to Wärtsilä of Finland ${ }^{[2]}$.

As a driving shipping power plant, the technical level and innovation of marine diesel engine has not only high economic benefits, but also the long-term environmental benefits. So, many countries invest continuously from the aspect of government decision-making. The project HERCULES (High Efficiency R\&D on Combustion with Ultra Low Emissions for Ships)-A/B/C of the European Union is more representative. The project focused within the eu's top manufacturers of 2stroke marine diesel engine, the team of universities and research institutes, from 2004 to 2015,it carried out thorough research successively in three phases about energy conservation and emissions reduction of two-stroke diesel engine, security stability, etc. ,which gave a great push and improvement for basic research and practical application of 2-stroke marine diesel engine ${ }^{[3]}$.With the development of computational fluid dynamics, there has been numerical simulation of combustion process in cylinder of internal combustion engine from the late 1970s. Although the computational fluid dynamics simulation of working process about the internal combustion engine is considered to be the most challenging direction, it has a good prediction accuracy after nearly 40 years development, it has become the important means researching internal combustion engine at present. The existing popular commercial software of computational fluid mechanics about the internal combustion engine include: Star CD of CD-Adapco company, FIRE of AVL company, and FLUENT,CFX of ANSYS company, in addition, there are KIVA which runs on open source program and the internal combustion engine simulation module of Open FOAM. The calculating program has played a huge role in promoting the application of computational fluid dynamics numerical simulation about internal combustion engine ${ }^{[4]}$

Two-stroke marine diesel engine uses a dc scavenging method at present. The scavenging process parameter settings and control directly affect the quality of the fresh air in the cylinder, in turn affect the level about combustion and exhaust gas quality of fuel in the cylinder; it has important influence on the performance of the marine diesel engine. The paper will discuss the scavenging process of large 2-stroke marine diesel engine using the ANSYS FLUENT software.

The research about scavenging of 2-stroke marine diesel engine began in the 1990s. Nakagawa ${ }^{[5]}$ studied the scavenge port Angle using a laser velocimeter, and come to the conclusion, the maximum rotating speed of compressed air at top dead center is directly proportional to the sine value of scavenge port angle, it can get a higher scavenging quality and sufficient rotation strength by scavenge port angle combined with the size. Litke ${ }^{[6]}$ compared the scavenge port scheme with liquid of three companies, MAN B\&W, Wärtsilä and Mitsubishi, under the same scavenging port angle, Litke considers Mitsubishi has the best performance. Sher etc. ${ }^{[7]}$ simplify the problem, set the scavenging process for steady flow state, compared the hotline detector data with CFD results, and the results comparison error is bigger, due to the standards adopted by the $\mathrm{k}$ - e model is not accurate. Pergolesi ${ }^{[8]}$, Obeidat $^{[9]}$ and Haider ${ }^{[10]}$ of Denmark technical university all tested detailedly a transparent institution similar marine 
2-stroke diesel engine scavenging port and cylinder model using particle speedometer and laser velocimeter, and compared the results with CFD calculation, but it got good results until Hemmingsen ${ }^{[11]}$ adopted Star CCM + later. Lamas $^{[12]}$ adopted 7S50MC scavenging pressure test data of MAN B\&W and compared with the calculation results of ANSYS FLUENT, and good results are obtained. While Sigurdsson ${ }^{[13]}$ compared the test data about the test model 4T50ME-X of MAN B\&W with predicted results of Star CD, pressure error on the check point is $14 \%$.While changing the equation of state to real gas state equation model, pressure error on the check point is still up $6.5 \%$.

\section{The Geometric Model And BAsic Settings}

Accurate geometric modeling is a critical step in numerical simulation, table I is basic parameters of large 2-stroke marine diesel engine MAN B\&W S60MC - C6, and Fig. 1 is its geometry of cylinder head and scavenge port. In order to make the grid and calculation simple, vent is set before the exhaust valve set. So, the hexahedron mesh can be adopted in the whole computing area. Fig. 2 is the grids of the cylinder profile at top dead center and scavenge port place. The grid scale near the top dead center and scavenge port place is $0.5 \mathrm{~cm}$, the rest size of the grid is $1.0 \mathrm{~cm}$. In addition, in order to there is no the grid of zero height when the exhaust valve and valve seat contact, assume that they already touch when their distance is less than $1 \mathrm{~mm}$, and at this time, the area above the exhaust valve is set to inactive state, not only there have no adverse effects to calculation, but eliminate the area which don't participate in calculation after the closing, the computing cost is saved.

TABLE I. THE BASIC PARAMETERS OF MAN B\&W S60MC-C6

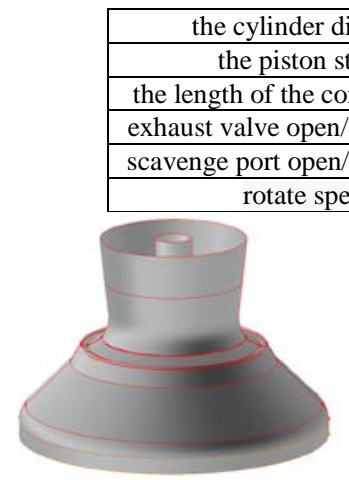

(a) (b)

Fig. 1. The geometry of cylinder head and scavenge port

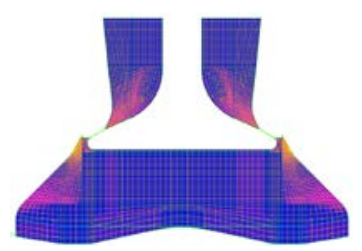

(a)

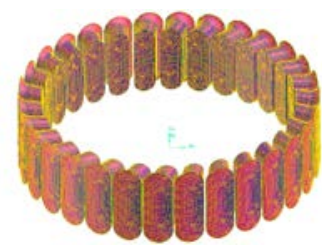

(b)
Fig. 2. Grids of the cylinder profile at top dead center and scavenge port place
TABLE II. THE BENCH TEST DATA OF MAN B\&W S60MC-C6

\begin{tabular}{|c|c|}
\hline scavenging absolute pressure (Pa) & 393800 \\
\hline the scavenging temperature (K) & 315 \\
\hline absolute pressure in vent (Pa) & 375800 \\
\hline $\begin{array}{c}\text { temperature in vent (K) } \\
\text { 110 angle (Pa) }\end{array}$ & 683 \\
\hline $\begin{array}{c}\text { absolute pressure in cylinder of calculation starting point } \\
\text { angle (K) }\end{array}$ & 997788 \\
\hline temperature in cylinder of calculation starting point 110 & 1100 \\
\hline
\end{tabular}

Table II is data of the diesel engine measured on the bench test under the corresponding rotational speed. In order to include the whole scavenging process, calculation started from $110^{\circ}$ angle until $290^{\circ}$ angle which vent closed completely. It is important to note, in an instant when the exhaust valve opens and closes just now, there was a problem about convergence of solver because the pressure gradient instantaneous value was very big. In order to avoid this situation, the smaller time step (0.01CAD/ $/ \Delta \mathrm{t})$ was adopted in test, and this method is also adopted by $\mathrm{Kim}{ }^{[14]}$. The time step of the rest time is $0.1 \mathrm{CAD} / \Delta \mathrm{t}$. The turbulence model was RNG k-e model, surface was considered as non-equilibrium wall function. State equation was comparing the ideal gas state equation and state equation of real gas, Finite-Rate / Eddy-Dissipation model was used to analyze material transport of each composition. The specific equation and detailed description was in AYSYS ${ }^{[i 5]}$.

\section{THE RESUlTS AND ANALYSIS}

The error between experimental data and the calculated results was caused by the ideal gas state equation used in the calculation model, as mentioned in Lamas, paper, etc. In order to verify their guesses, this paper respectively used the ideal gas state equation and the real gas state equation to calculate and compare. Fig. 3 is the result of calculation respectively using the ideal gas state equation and the real gas state equation. We can find that the two lines almost overlap together.

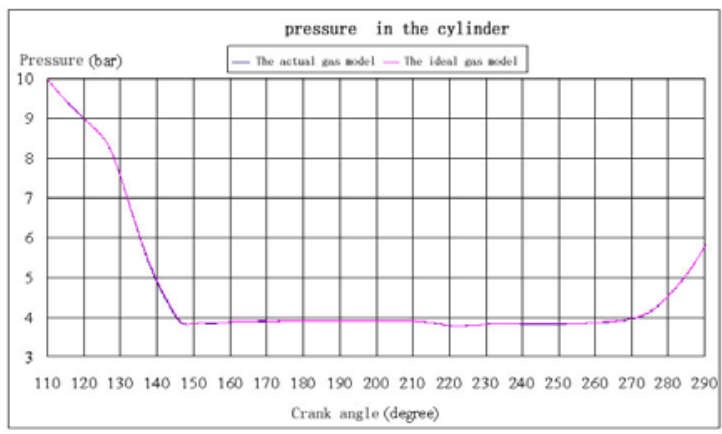

Fig. 3. The stress results calculated by the ideal gas state equation and the real gas state equation

Table III lists comparison of the pressure of starting point, temperature and percentage deviation of the quality of gas in cylinder calculated with two kinds of state equation. We can see that the gas quality deviation of the ideal gas state equation and the real gas state equation is $0.25 \%$ when initializing the starting point of calculation (110 angle corner). The deviation is so small that can almost be ignored. But deviation of pressure in cylinder is $0.01 \%$ at calculating terminal point (290 
angle corner), deviation of temperature and quality of gas inside the cylinder is at $1 \%$ order of magnitude. It follows that there are almost no differences between the results of the two kinds of state equation just for scavenging process. The state of the gas in cylinder in scavenging process can be considered as ideal gas because it still has a distance away from the critical state. On the same condition, computing time of using the real gas state equation then is about three times as long as time of the ideal gas state equation. This is because the solution of actual state equation is complex than the ideal gas equation, and the amount of state equations involved, such as density, pressure, temperature, which all need be updated in solving equations in the whole calculation domain. As much as possible to reduce calculation error, the calculation results of this paper are all made of real gas state equation.

TABLE III. THE CALCULATION RESULTS DEVIATION PERCENTAGE OF TWO KINDS OF STATE EQUATION

\begin{tabular}{|c|c|c|c|c|c|c|}
\hline & \multicolumn{3}{|c|}{110 CAD } & \multicolumn{2}{c|}{ 290 CAD } \\
\cline { 2 - 7 } & $\begin{array}{c}\text { pressure } \\
(\mathrm{bar})\end{array}$ & $\begin{array}{c}\text { temperature } \\
(\mathrm{K})\end{array}$ & $\begin{array}{c}\text { quality of gas in } \\
\text { cylinder }(\mathrm{kg})\end{array}$ & $\begin{array}{c}\text { pressure } \\
(\mathrm{bar})\end{array}$ & $\begin{array}{c}\text { temperature } \\
(\mathrm{K})\end{array}$ & $\begin{array}{c}\text { quality of gas in } \\
\text { cylinder }(\mathrm{kg})\end{array}$ \\
\hline the ideal gas & 9.9779 & 1100 & 1.780 & 5.7788 & 408 & 1.639 \\
\hline the actual gas & 9.9779 & 1100 & 1.776 & 5.7781 & 403 & 1.657 \\
\hline deviation (\%) & 0.00 & 0.00 & 0.25 & 0.01 & 1.16 & -1.09 \\
\hline
\end{tabular}

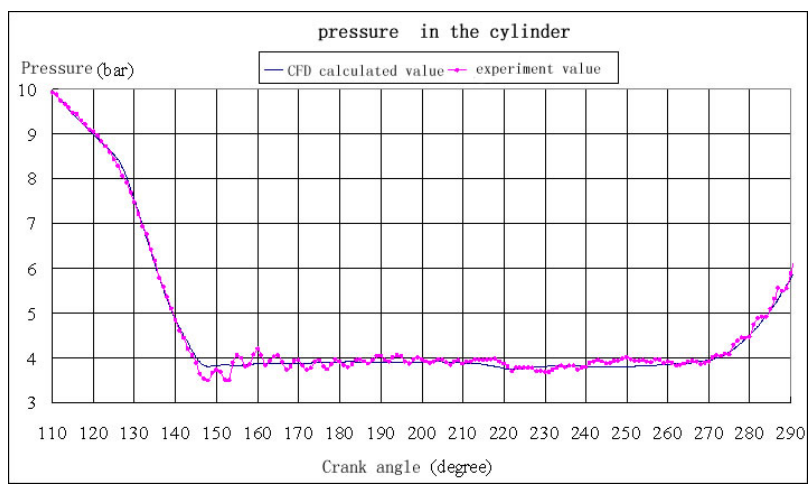

Fig. 4. The comparison of pressure in cylinder calculated with experimental results

Fig. 4 is the comparison of pressure in cylinder calculated with experimental results. Compared with the calculated results, the pressures measured in experiment are obvious oscillating. Scavenging pressure is set for the fixed value in the calculation, which is one reason for the error, Lamas believes. It can be found from the stress contrast of $220^{\circ}$ crank corner in Fig. 4 that test results show a relatively large fluctuation when scavenging port is turned off on $218^{\circ}$ crank corner. Pressure change relatively gradually after an average volume in CFD calculation. Pressure is very sensitive in the test process. Considering the possible error and uncertainty in experimental measurement and numerical calculation, it can draw a conclusion that the calculation result in this paper is satisfactory.

Fig. 5 is the gas discharge of entering into scavenging port and flowing through vent. Positive value is flowing into and negative value is out of. It can see that there is a backflow phenomenon, gas in cylinder flowing into the scavenge box because the air in the cylinder pressure is bigger than scavenging pressure at $142^{\circ}$ crank angle, which scavenge port just opens about within $5^{\circ}$. Fig. 6(a)-6(d) is the flow of gas in cylinder respectively at $145^{\circ}, 160^{\circ}$, $180^{\circ}$ and $220^{\circ}$ crank angle. After a temporary backflow, gas pressure in cylinder is greater than gas pressure of scavenge box, at the top of gas is swept out of the vent under the "air cushion" of strong cyclone for tilting scavenge port. When the scavenging port closed at $218^{\circ}$, exhaust gas in cylinder has been dominated by fresh air, which reduced the fresh air mixing with waste gas of combustion in cylinder. That is why the scavenging port designed to be a certain tilt angle. It can be seen, the CFD calculation results in this paper not only can effectively predict the change of gas pressure in cylinder, and the flow details of gas in cylinder can also be well reproduced. It can be used to optimize the geometric shapes of scavenging port and scavenging pressure, temperature, etc.

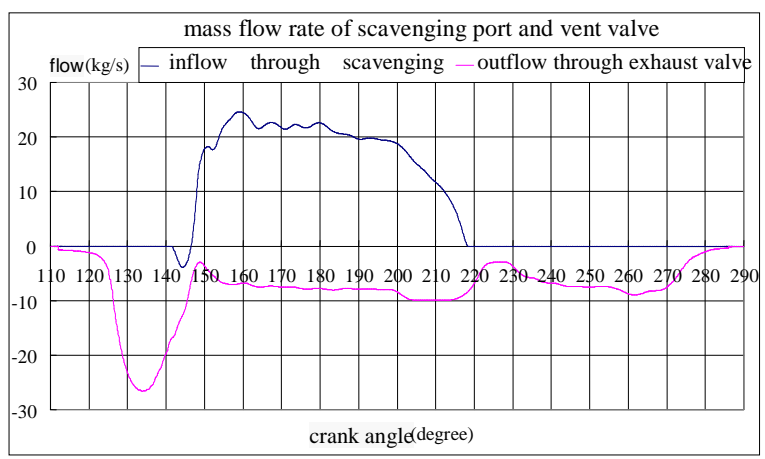

Fig. 5. Gas discharge of inflow and outflow

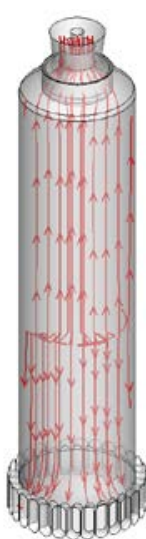

(a) $145^{\circ}$

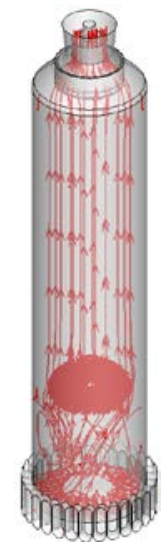

(b) $160^{\circ}$

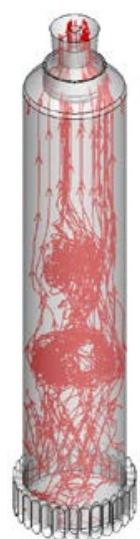

(c) $180^{\circ}$

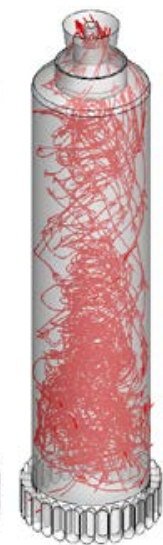

(d) $220^{\circ}$
Fig. 6. Flow of gas in cylinder at different crank angle 


\section{CONCLUSION}

The author of this paper calculated the scavenging process of large 2-stroke marine diesel engine, MAN B\&W S60MC-C6 with CFD. The stress was compared with the test data, and the result is good. The following points was proved:

1) There are almost no differences of the calculation results between the ideal gas state equation and the real gas state equation in scavenging process, because the gas in scavenging air condition has larger difference with critical state. But the calculation time can be significantly shorten with the ideal gas state equation.

2) Considering the error of the experiment and numerical calculation, RNG k-e turbulence model and Finite-Rate / Eddy-Dissipation mass transportation model can predict accurately the flow state in cylinder and pressure values.

3) CFD calculation results can well reproduced the flow details of gas in cylinder. It can be used to optimize the geometric model of large 2-stroke marine diesel engine and scavenging state.

\section{REFERENCE}

[1] Woodyard, D., 2009. Pounder's Marine Diesel Engines and Gas Turbines, 9th Edition, Elsevier Butterworth-Heinemann.

[2] Wärtsilä,2014. http://www.wartsila.com/en/investors/markets/market-shares

[3] Kyrtatos, N. P., 2012. HERCULES A-B-C, A 10-Year Major R\&D Effort towards the Next Generation Large Marine Diesel Engines. Procedia - Social and Behavioral Sciences, 48, 1068-1077.

[4] Lakshminarayanan, P. A., Aghav, Y. V., 2010. Modelling Diesel Combustion, Springer Science+Business Media B. V.
[5] Nakagawa, H., Kato, S., Tateishi, M., Adachi, T., Tsujimura, H., Nakashima, M., 1990. Airflow in the Cylinder of a 2-Stroke Cycle Uniflow Scavenging Diesel Engine during Compression Stroke. JSME International Journal, 33(3), 591-598.

[6] Litke, B., 1999. The influence of inlet angles in inlet ports on the scavenging process in two-stroke uniflow-scavenged engine. 3rd International Conference on Marine Technology (ODRA 99), SZCZECIN, POLAND, 247-252.

[7] Sher, E., Hossain, I., Zhang, Q., Winterbone, D. E., 1991. Calculations and Measurements in the Cylinder of a Two-Stroke Uniflow-Scavenged Engine under Steady Flow Conditions. Experimental Thermal and Fluid Science, 4, 418-431.

[8] Pergolesi, F., 2009. Scavenging Flow in a Model of a Two-Stroke Diesel Engine. Master Thesis, Technical University of Denmark.

[9] Obeidat, A., Haider, S., Ingvorsen, K. M., Meyer, K. E., Walther, J. H., 2010. Influence of Piston Displacement on the Scavenging and Swirling Flow in Two-Stroke Diesel Engines. 23rd Nordic Seminar on Computational Mechanics, Stockholm.

[10] Haider, S., 2011. Experimental and Numerical Study of Swirling Flow in Scavenging Process for 2-Stroke Marine Diesel Engines. PhD Thesis, Technical University of Denmark

[11] Hemmingsen, C. S., Ingvorsen, K. M., Walther, J. H., Mayer, S., 2013. Swirling Flow in a Two-Stroke Marine Diesel Engine. Proceedings of the 26th Nordic Seminar on Computational Mechanics, Oslo.

[12] Lamas, M. I., Videl, C. G. R., 2012. Computational Fluid Dynamics Analysis of the Scavenging Process in the MAN B\&W 7S50MC Two-Stroke Marine Diesel Engine. Journal of Ship Research, 56(3), 154-161.

[13] Sigurdsson, E., Ingvorsen, K. M., Jensen, M. V., Matlok, S., Mayer, S., Walther, J. H., 2014. Numerical Analysis of the Scavenge Flow and Convective Heat Transfer in Large Two-Stroke Marine Diesel Engines. Applied Energy, 123, 37-46.

[14] Kim, S. C., Lee, D. H., Cho, Y. S., 2001. The Comparison about CFD-Simulation \& Measurement Result of Large Two-Stroke Diesel Engine. CIMAC Congress 2001

[15] ANSYS, 2012. ANSYS FLUENT Theory Guide. 